\title{
CARACTERIZAÇÃO DO MERCADO CONSUMIDOR DE PRODUTOS ORGÂNICOS EM RIO PARANAÍBA-MG
}

\section{CHARACTERIZATION OF THE CONSUMER MARKET FOR ORGANIC PRODUCTS IN RIO PARANAÍBA-MG}

\author{
L. I. S. SILVA ${ }^{1}$, A. L. OLIVEIRA ${ }^{1}$, M. P. SOUTO ${ }^{1}$, L. C. ALVES ${ }^{1}$ \\ ${ }^{1}$ Instituto de Ciências Agrárias. Universidade Federal de Viçosa - Campus Rio Paranaíba \\ E-mail: ligia.ines@ufv.br
}

\author{
article info \\ Article history: \\ Received 12 May 2017 \\ Accepted 3 August 2017 \\ Available online 20 September 2017
}

\author{
PALAVRAS-CHAVE: Orgânicos; Mercado; Demanda.
KEYWORDS: Organic; Marketplace; Demand.
}

RESUMO: Este trabalho teve como objetivo caracterizar o mercado consumidor, sua percepção $e$ conhecimento sobre alimentos orgânicos em Rio Paranaíba - MG. Foram aplicados 188 questionários estruturados em estabelecimentos comerciais como supermercados e sacolões, sendo um questionário para cada participante e verificou-se que a maior parte dos consumidores são pessoas adultas, mulheres, de nível médio. Observou-se na pesquisa uma demanda por produtos orgânicos no mercado de Rio Paranaíba, sendo a indisponibilidade destes produtos o maior fator que limita esse consumo. Como grande porção dos participantes apresentou conhecimento superficial sobre o que é um produto orgânico e como identificá-lo na gôndola, ficou evidente a necessidade de maiores esclarecimentos sobre o assunto.

\begin{abstract}
This work aimed to characterize the consumer market, its perception and knowledge about organic food in Rio Paranaiba - MG. 188 structured questionnaires were applied in commercial establishments such as supermarkets and bakeries, with a questionnaire for each participant and it was verified that the majority of the consumers are adults, women, mid-level. A demand for organic products in the Rio Paranaiba market was observed in the research, being the unavailability of these products the biggest factor that limits this consumption. As a large portion of the participants presented superficial knowledge about what an organic product is and how to identify it on the gondola, it became clear that there is a need for further clarification on the subject.
\end{abstract}

\section{INTRODUÇÃO}

Tem havido com o passar do tempo crescente aumento na preocupação com saúde e qualidade de vida, sendo a procura por alimentos mais saudáveis, livres de aditivos e agrotóxicos cada vez maior. Por essa razão, a demanda por alimentos orgânicos vem crescendo nos últimos anos.

De acordo com a Lei $\mathrm{n}^{0} 10.831$, de 23 de dezembro de 2003, considera-se produto orgânico, seja ele in natura ou processado, aquele obtido em sistema orgânico de produção 


\section{The Journal of Engineering and Exact Sciences - \\ JCEC}

ISSN: 2527-1075

agropecuário ou oriundo de processo extrativista sustentável e não prejudicial ao ecossistema local. Esses são isentos de agrotóxicos, fertilizantes sintéticos e transgênicos.

Com estudos sobre o comportamento e perfil de consumidores orgânicos é possível aperfeiçoar o processo de comercialização e ainda aumentar o consumo. Os fatores que influenciam na compra do produto e quais os produtos com maior procura são informações necessárias para identificação de oportunidades de mercado (BERTOLDI, 2012).

O objetivo deste trabalho foi caracterizar o mercado consumidor, sua percepção e conhecimento sobre alimentos orgânicos em Rio Paranaíba.

\section{MATERIAL E MÉTODOS}

Utilizou-se um método de pesquisa descritiva com aplicação individual de questionários estruturados. Foram aplicados 188 questionários a consumidores diferentes em quatro estabelecimentos comerciais, sendo eles dois supermercados e dois sacolões, com o objetivo de identificar o perfil desses consumidores. A pesquisa foi realizada no período de abril a junho de 2016. Os entrevistados foram escolhidos aleatoriamente. Observaram-se questões relacionadas a sexo, idade, renda, escolaridade, frequência de compra, entre outros questionamentos.

A interação pesquisador - consumidor foi minimizada através do não esclarecimento a respeito dos itens abordados no questionário, sendo explicado apenas aos participantes a natureza acadêmica da pesquisa.

\section{RESULTADOS E DISCUSSÃO}

Quando questionado o motivo que levaria o consumidor a comprar um alimento mais caro, a maioria $(43,61 \%)$ dos participantes relatou que comprariam caso o produto fosse mais nutritivo e/ou saudável. Tal resultado demonstra a crescente preocupação com a qualidade de vida e bem estar. Trabalhando com o mercado consumidor de orgânicos em Belo Horizonte, BERTOLDI (2012) obteve resultados que vão de encontro a essa questão, onde a maioria dos entrevistados, além de preferirem alimento orgânico, realizavam exercício físico regularmente ou já haviam feito alguma dieta.

Com relação ao que é um produto orgânico, muitos participantes não souberam ou responderam ser um alimento caseiro produzido em pequenas hortas. Isso demonstra a falta de conhecimento do que realmente vem a ser um alimento orgânico.

Dentre os entrevistados, mais de $56 \%$ são do sexo feminino. $76,59 \%$ comprariam um alimento orgânico por fazer bem à saúde.

De acordo com a Figura 1, a maioria tem idade entre 20 e 30 anos. Por estudantes universitários representar uma boa parcela da população do município, muitos entrevistados relataram possuir ensino superior, sendo poucos com pós-graduação. Porém, o ensino médio compreende a maior parcela. 


\section{The Journal of Engineering and Exact Sciences -}

JCEC

ISSN: 2527-1075

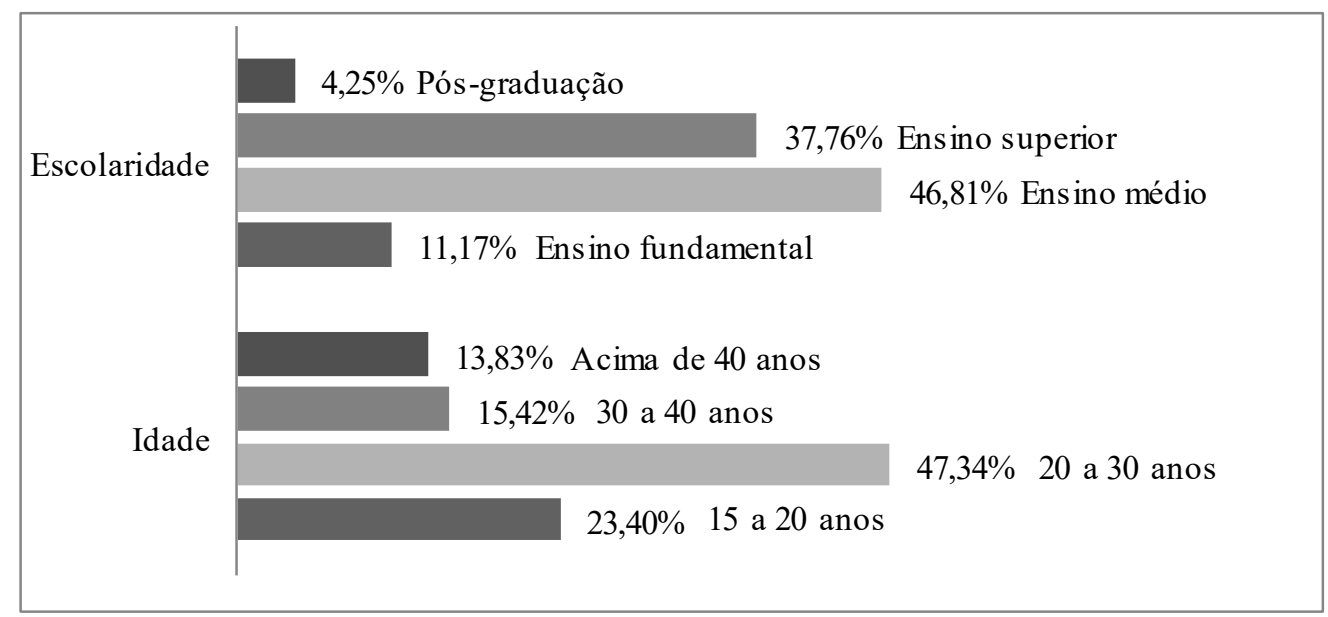

Figura 1 - Perfil de escolaridade e idade dos consumidores.

Em relação ao preço do produto, 95,74\% dos entrevistados comprariam o produto orgânico caso custasse o mesmo preço do convencional. A busca pelo preço baixo ainda é mais forte no mercado levando o consumidor a não optar pelos alimentos orgânicos, o qual ainda se encontra mais caro que o convencional.

Analisando a Figura 2, os grupos de alimentos orgânicos de maior interesse entre os entrevistados são verduras e legumes $(60,1 \%)$ e frutas $(30,85 \%)$. Cereais e massas, produtos de origem animal, bebidas biscoitos e doces, menos de $20 \%$ dos entrevistados teriam interesse. Esses dados comprovam que ainda há falta de informação sobre quais produtos podem ser orgânicos. Entretanto, produtos de origem animal se encontram mais caros nas gôndolas dos mercados quando comparados com frutas e legumes.

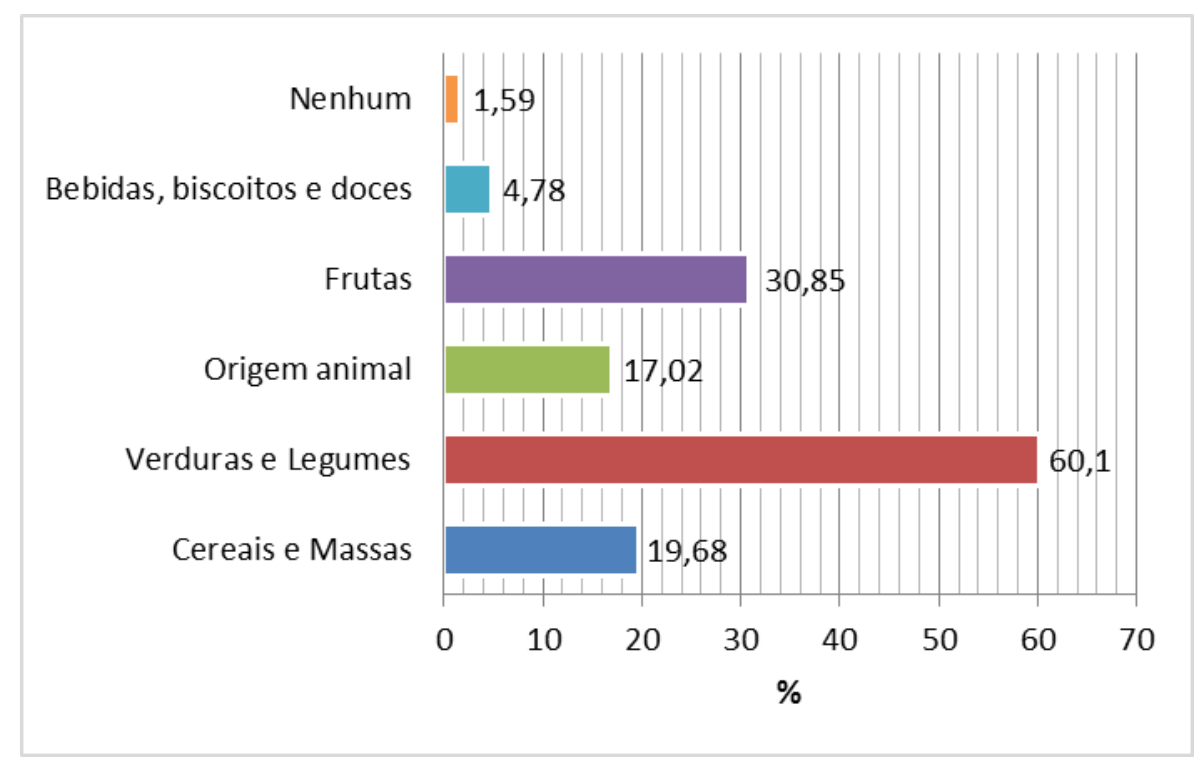

Figura 2 - Preferência dos consumidores em relação ao grupo de alimentos orgânicos. 


\section{The Journal of Engineering and Exact Sciences - \\ JCEC \\ ISSN: 2527-1075}

Pela Figura 3, percebe-se que 75,53\% dos entrevistados estariam dispostos a pagar a mais $25 \%$ por um alimento orgânico em relação a um alimento convencional. Ainda que a preocupação com a saúde e bem estar esteja em alta, a população não está disposta a pagar altos preços por produtos orgânicos.

De acordo com o SEBRAE (2015), a produção orgânica nacional vem crescendo mais de $20 \%$ ao ano. No entanto, esse crescimento é inferior à demanda pelos produtos. O quadro se agrava pelo fato de que $70 \%$ da produção é exportada para a Europa. O desequilíbrio entre a capacidade de produção e procura pelos produtos na prateleira tem sido um problema para os varejistas. As menores cidades no Brasil têm em comum a dificuldade de encontrar fornecedores de produtos orgânicos para atender ao interesse crescente de seus consumidores. A partir dessa informação, os dados coletados são confirmados, em que $52,66 \%$ dos entrevistados não encontram produtos orgânicos para comprar.

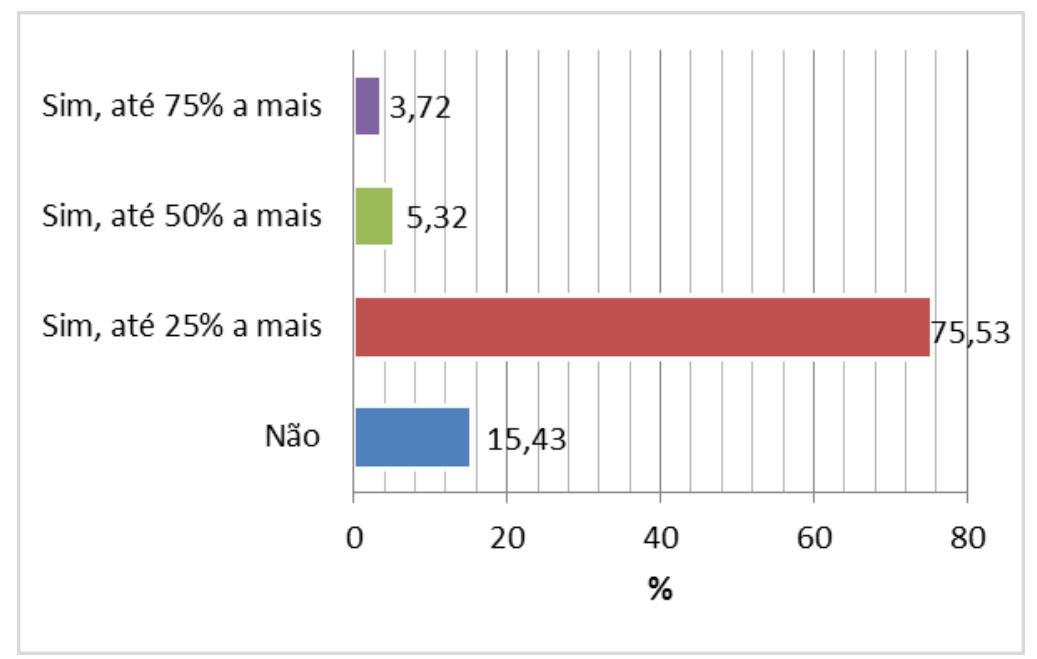

Figura 3 - Respostas dos consumidores sobre o quão estariam dispostos a pagar a mais por um alimento orgânico.

\section{CONCLUSÕES}

Como parte dos consumidores apresentou conhecimento superficial sobre o que é um produto orgânico, fica evidente a necessidade de maiores esclarecimentos sobre o assunto e também uma maior oferta desses produtos nas gôndolas dos supermercados para os já adeptos. A indisponibilidade de produtos orgânicos no comércio de Rio Paranaíba é o maior fator limitante ao consumo.

\section{REFERÊNCIAS}

BERTOLDI, M. C. Atitudes e motivação em relação ao consumo de alimentos orgânicos em Belo Horizonte - MG. Braz. J. Food Technol., IV SSA, maio 2012, p. 31-40. 
ISSN: 2527-1075

BRASIL. Ministério da Agricultura e do Abastecimento. Lei $\mathbf{n}^{0} \mathbf{1 0 . 8 3 1}$, de 23 de dezembro de 2003. Dispõe sobre a agricultura orgânica e dá outras providências. Diário Oficial da República Federativa do Brasil, Brasília, DF, 24 dez. 2003. Seção 1, n. 250, p. 8.

SEBRAE, 2015. O mercado para produtos orgânicos está aquecido. Disponível em: < http://www.sebrae.com.br/sites/PortalSebrae/artigos/o-mercado-para-os-produtosorganicos-esta-aquecido,5f48897d3f94e410VgnVCM1000003b74010aRCRD>. Acesso em: 28/03/2017 